\title{
Job Strain, Work Rumination and Sleep in School Teachers
}

\author{
Mark Cropley ${ }^{1}$, Derk-Jan Dijk², and Neil Stanley ${ }^{2}$ \\ ${ }^{1}$ Department of Psychology, School of Human Sciences, ${ }^{2}$ Surrey Sleep Research \\ Centre, School of Biomedical and Molecular Sciences, University of Surrey, UK.
}

Running Head: Work rumination and Sleep

Key words: Job strain, work rumination, school teachers, diary

Correspondence to

Dr Mark Cropley

Department of Psychology

School of Human Sciences

University of Surrey 
Guildford, Surrey

GU2 7XH, UK

\begin{abstract}
The objectives of this study were, firstly, to examine the association between job strain and sleep quality in a sample of primary and secondary school teachers and, secondly, to assess whether the relationship between job strain and sleep quality is mediated or moderated by an individual's inability to 'switch-off' from work related issues during leisure time. School teachers $(\mathrm{N}=143)$ completed an hourly record of their work related thoughts over a workday evening between $5 \mathrm{pm}$ and bedtime, and then rated their sleep quality the following morning. Individuals were classified as reporting high $(n=462)$ or low $(n=52)$ job strain using predetermined cut-off scores.

Consistent with previous research, the results showed that both groups demonstrated a degree of unwinding and disengagement from work issues over the evening. However, compared to the low job strain group, the high job strain teachers took longer to unwind and ruminated more about work related issues, over the whole evening, including bedtime. There was no difference in total sleep time between the groups, but high job strain individuals reported poorer sleep quality compared to low job strain individuals. With respect to the second objective, across the whole sample $(\mathrm{N}=143)$, work rumination and job strain were significantly correlated with sleep quality, but work rumination was not found to mediate, or moderate the relationship between job strain and sleep quality. It was speculated that the initial low contribution of job strain to sleep quality $(r=-.18)$ may have contributed to this null finding. The current findings may have implications for how we assess and manage sleep disturbance in stressed workers.
\end{abstract}




\section{INTRODUCTION}

One of the most influential occupational theories over the last two decades has been the Job Strain model as formulated by Karasek and Theorell (1990). They suggest that health risks are greater among people who experience high job demands, coupled with low control over how the work is conducted. Demanding jobs, accompanied with low decision latitude, have been associated with a range of physical and psychological stress related disorders (Belkic, Landsbergis, Schnall, \& Baker, 2004; Cropley, Steptoe, \& Joekes, 1999; Stansfeld, North, White, \& Marmot, 1995). Occupational induced stress can often spill-over into non-work time and high job strain individuals in particular have been found to demonstrate delayed psychological and physiological recovery following work (Steptoe, Cropley, \& Joekes, 1999; Cropley \& Millward Purvis, 2003; Rau, Georgiades, Fredrikson, Lemne, \& de Faire, 2001). In one study, for example, Steptoe et al., (1999) investigated the association between cardiovascular disease risk and job strain in a sample of primary and secondary school teachers. The teachers had their blood pressure (BP) monitored over the working day and evening, and readings were accompanied with diary ratings of personal control and stress. It was found that there were no significant differences in BP over the working day between the job strain groups, however BP decreased to a greater extent in the evening in the low job strain group. The results were not attributable to posture, age, sex or body mass index.

The mechanism by which high job strain contributed to sustained evening arousal in this study was not ascertained. However Cropley and Millward Purvis (2003) recently speculated that high job strain individuals may take longer to physiologically unwind following a day’s work because they fail to cognitively 'switch-off' after work, and engage in more ruminative thinking about work related issues once paid work is completed. In order to test this hypothesis, school teachers were asked to complete a short structured diary about their work related thoughts from 5 pm until 9 pm. The findings revealed that both high and low job strain workers showed a certain degree of unwinding and disengagement from work related thoughts during the evening, yet high 
job strain workers nevertheless took longer to unwind and ruminated more about work related issues, relative to their low job strain colleagues. These findings were independent of work patterns during the evening. A limitation to this study, however, was that no outcome variable was measured, so it is not clear what role work rumination plays in the path between job strain and well-being.

The present study was designed to replicate and extend this research in two ways. Firstly, we examined the mechanisms by means of which work rumination contributes to sustained cognitive arousal by extending the time frame in which work rumination is measured. We did this by assessing work ruminative thoughts in high and low job strain workers across the whole evening, until bedtime. Secondly, we wished to examine the association between work rumination and sleep quality and in particular whether work rumination mediates or moderates the relationship between job strain and sleep.

There are many conceptualisations of rumination. According to Martin and Tesser (1989) rumination is a generic term which covers a wide range of perseverative thinking. Such thinking, they argue, is characterised: (1) by its frequency, (2) as involving automatic and controlled processing, and (3) for hindering goal attainment. Rumination has been associated with different psychological states including: depression (Nolen-Hoeksema, 1991), anxiety (Mellings \& Alden, 2000) anger (Rusting \& Nolen-Hoeksema, 1998; Hogan \& Linden, 2004), and negative affect (Thomsen, Mehlsen, Olesen, Hokland, Viidik, Avlund, \& Zachariae, 2004). Rumination has also been associated with poor physical health (Thomsen, et al., 2004), although the exact role rumination plays in the development and/or progression of physical and psychological disorders is yet to be determined.

There is much evidence to suggest that people tend to ruminate about symptoms of distress or their stressful situations (Lyubomirsky, Tucker, Caldwell \& Berg, 1999; NolenHoeksema, McBride, \& Larson, 1997). Alloy and colleagues have recently coined the term 'stress-reactive rumination' to describe the type of thinking that occurs following the exposure to 
stressful life experiences (Alloy, Abramson, Hogan, Whitehouse, Rose, et al., 2000; Robinson \& Alloy, 2003), and ruminating individuals have been shown to display slower physical recovery after working on a stressful task (Roger \& Jamieson, 1988).

Coping responses are known to affect the relationship between stress and well-being (Steptoe, 1991) and rumination has also been conceptualized as a maladaptive coping response (Higgins \& Endler, 1995; Papageorgiou \& Wells, 2004; Thomsen, et al., 2004). According to Lazarus \& Folkman (1984) coping can be divided into two board categories: problem-focussed coping and emotion-focussed coping. In response to a stressor, a problem-focussed approach involves taking direct action, the goal being to reduce either the stressor or enhance resources necessary to deal with it effectively. On the other hand, emotion-focussed coping aims to regulate or reduce the emotional consequence of the stressor. In response to a stressor, an individual using an emotion-focussing approach, may try to control their feelings by distracting attention away from the stressor, using wishful thinking, or they may cognitively re-evaluate their situation. In line with previous conceptualizations, rumination in the present study is considered to an emotional-focussed coping response (Higgins \& Endler, 1995; Thomsen et al., 2004).

Sleep is one of the most important recovery mechanisms available to humans, allowing for recovery from daily strains, and therefore a prerequisite for optimal daily functioning and health. The literature suggests that sleep must be continuous for it to be restorative (Walsh \& Lindblom, 2000), and sleep loss and sleep disturbance lead to performance decrements, fatigue, mood changes and immune function impairment (Harrison \& Horne, 1999; Rogers, Szuba, Staab, Evans \& Dinges, 2001). Even moderate sleep loss is associated with deficits in alertness and performance (Dinges, Pack, Williams, Gillen, Powell, et al, 1997; Jewett, Dijk, Kronauer \& Dinges, 1999). Although there are many paths to insomnia, there appears to be a degree of consensus within the sleep literature that intrusive cognitions may contribute to sleep disturbance. For example, cognitive arousal at bedtime appears to be linked with insomnia (Harvey, 2000; Gross \& Borkovec, 1982), and work related worries appear to contribute to self-reported sleep 
disturbance (Åkerstedt, Knutsson, Westerholm, Theorell, Alfredsson \& Kecklund, 2002). Studies that have specifically examined rumination and insomnia have found a relationship between rumination and sleep quality in both healthy individuals (Thomsen, Mehlsen, Christensen \& Zachariae, 2003) and psychiatric patients (Bertelson \& Monroe, 1979; Kales, Caldwell, Soldatos, Bixler \& Kales, 1983). Thus, there is strong evidence that cognitive arousal at bedtime is associated with increased sleep disturbance.

Coping resources have been found to mediate and moderate the link between stress and sleep (Åkerstedt et al., 2002; Sadeh, Keinan, \& Daon, 2004), so it is probable that work rumination would both mediate and moderate the relationship between job strain and sleep. A mediation variable is one which intervenes or accounts for the relationship between a predictor variable and an outcome variable. Mediation is a hypothesized causal chain where one variable, affects another variable, that it turn affects a third variable. By contrast, a moderating variable is a third variable which affects the direction and/or strength of the relationship between two other variables (Baron \& Kenny, 1986).

The theoretical link between job strain, rumination and sleep was examined in the present study within a population of school teachers. School teaching is considered to be a high stress occupation (Travers \& Cooper, 1996), involving high commitment and school teachers have been shown to find it difficult to recuperate after work (Aronsson, Svensson, \& Gustafsson, 2003), and to be distracted by work issues when at home (Cardenas, Major, \& Bernas, 2004). Compared to the general population, teachers with high job strain have also been found to report poorer sleep (Cropley, et al., 1999). In the present study individuals were instructed to complete a structured rumination and sleep diary which assessed work ruminative thoughts over a workday evening, and self-reported sleep the following morning. It was predicted that relative to low job strain, high job strain individuals would take longer to unwind following work and would ruminate more about work issues over the evening up to bedtime (Hypothesis 1). As coping resources have been found to mediate and moderate the link between stress and sleep (Åkerstedt et al., 2002; Sadeh et 
al., 2004), it was also predicted that work rumination would both mediate and moderate the relationship between job strain and sleep (Hypothesis 2).

\section{METHOD}

\section{Participants}

Participants were recruited from primary and secondary schools in Surrey, England. Each school was initially contacted by letter explaining the nature of the study, and a member of the research team gave a short presentation to those teachers interested in participating. Individuals who volunteered, and were full-time, were given an information pack together with the diary and a freepost return envelope. A total of 170 diaries were distributed, and 151 were returned by the specified deadline, amounting to a response rate of $88.8 \%$. Five diaries were excluded because participants reported being disturbed by external factors whilst sleeping (e.g., awoken by a child or a phone call), or they reported taking sleep medication. A further 3 diaries were excluded because of incomplete information. The final sample consisted of 143 teachers whose age ranged from 21 - 59 years, with a mean of 38.61 years $(S D=11.23$ years). The majority of the sample (74\%) worked in primary schools and the remaining 26\% were from secondary schools. They had been working in the teaching profession from 3 months to 34 years (mean 13.0 years). The sample was predominately female (83.2\%). Ninety-four (65.7\%) participants were married or living with their partner, 9 (6.3\%) were separated, divorced or widowed, and 40 (28\%) were single.

\section{Materials}

\section{Job Strain}

Job strain was assessed using a 10-item self-report measure adapted from Karasek and Theorell (1990). Three items concern perceived job control (e.g., 'I have freedom to decide what I do in my job’), three items concern job demands (e.g., 'The pace of work in my job is very intense’), 
and four items refer to skill utilisation (e.g., 'My job involves me learning new things'). Participants rate each statement along a 4-point scale ranging from 1-strongly disagree to 4strongly agree. The job strain score is computed as job strain = job demand / (job control + skill utilisation). The validity of this measure has been demonstrated in a number of previous studies (e.g., Cropley \& Millward Purvis, 2003; Steptoe et al., 1999; Evans \& Steptoe, 2001; 2002). Classification of high and low job strain teachers followed Steptoe et al. (1999): high job strain above 13.3 (men) and 13.5 (women); and low job strain below 11.3 (men) and 12.4 (women). The internal consistency (Cronbach $\alpha$ ) for this measure was 0.75 .

\section{Work Rumination/sleep diary and procedure}

The work rumination and sleep questions were incorporated into a small diary that was completed over one workday evening and the following morning. Four work rumination questions were used: (1) ‘Did you think about work in the last hour?’ (2) ‘Did you think about future work, e.g. lessons, tomorrow?' (3) 'Did you think about things that had happened at work today or before today?' (4) 'Would you describe your thoughts in the last hour as repetitive/ recurring?’ Each was rated on a seven-point scale ranging from $1=$ not at all to $7=$ all the time. These questions are similar to those used by Cropley and Millward Purvis (2003). Participants were required to indicate their choice by circling an appropriate number. Each double page entry contained information relating to one hour. Additional questions sought information about location, posture, and activity. Ratings were made hourly from 5 pm until bedtime, and the data from the 4 rumination questions were averaged for each time point. The internal consistency (Cronbach $\alpha$ ) of the rumination scale over the evening was good: $5 \mathrm{pm}=.78,6 \mathrm{pm}=.79,7 \mathrm{pm}=.84,8 \mathrm{pm}=$ $.85,9 \mathrm{pm}=.86,10 \mathrm{pm}=.86$, bedtime $=.88$.

Upon awakening, participants reported how long they had slept and whether they had been purposefully woken during the night, e.g. because of childcare duties or telephone calls etc. They also answered a series of sleep quality questions: did you sleep throughout the night, was it 
difficult or easy to fall asleep, did you wake up early, did you wake up easily, did you dream, how refreshed did you feel in morning upon waking, how well did you sleep, and was your sleep restless or calm. These questions were rated on a seven-point scale with the lower number indicating poorer sleep. For example, ‘Was it difficult or easy to fall asleep?’ was rated from 1 very difficult to 7 very easy. Similar items have been used in previous sleep research (Åkerstedt, Hume, Minors, \& Waterhouse, 1994). Factor analysis was carried out on the 8 sleep quality questions. Three factors emerged with eigen values greater than one, together accounting for $70.5 \%$ of the variance. A varimax rotation was performed, variables were loaded on a single factor on the basis of the highest score. Items with a loading greater than 0.4 were retained. The first factor contained 5 items (did you sleep throughout the night, did you wake up early, difficult or easy to fall asleep, how well did you sleep, and was your sleep restless or calm), had an eigen value of 3.4 and accounted for $42 \%$ of the variance. The internal consistency (Cronbach $\alpha$ ) of this factor was good, .79, and the factor was labelled sleep quality. The second factor consisting of 2 items (wake up easily, and how refreshed were you after awakening) had an eigen value of 1.3, and accounted for $16 \%$ of the variance and the third factor (any dreams) accounted for $12.5 \%$, and had an eigen value of 1 , but contained only one item. As the second two factors contained only 2 and 1 item respectively, they were excluded from further analyses.

\section{Data analysis}

The main analyses are divided into three sections. The first section compares data from the high and low job strain groups on work rumination over the evening from 5pm to bedtime. The effect of job strain on work rumination was analysed using a Group (high/low job strain) X Time (5 pm, 6 pm, 7 pm, 8 pm, 9 pm, 10 pm, Bedtime), Repeated Measures ANOVA. Mean comparisons were computed using planned t-tests. The second set of analyses included the participants with intermediate ratings of job strain scores and reports correlations of demographic characteristics, work measures, work rumination and sleep $(\mathrm{N}=143)$. Tests for mediation and moderation are 
presented in the third section. Work ruminative data for the hour preceding bed is used in this analysis. Three participants in the low job strain group and three in the high job strain group reported working in the hour preceding sleep. However their data were left in this analysis, as omitting them made no difference to the overall pattern of results. Baron and Kenny (1986) proposed a 4-step process for testing mediation. To test whether work rumination mediates the relationship between job strain and sleep quality, for example, the following four regression equations need to be performed: (1) job strain should be related to sleep quality, (2) job strain should also be related to work rumination, and (3) rumination should be related to sleep quality. In the $4^{\text {th }}$ step, a regression equation is performed with both job strain and rumination entered to predict sleep quality. If rumination, but not job strain, continues to affect sleep quality, this is consistent with a full mediation model. If rumination continues to affect sleep quality, after controlling for the direct effects of job strain, but job strain continues to be associated with sleep quality (albeit with reduced variance) this is consistent with a partial mediation model. By contrast, a moderating variable, as stated in the introduction, is a third variable which affects the relationship between two other variables. The underlying assumption here is that the effect of an independent variable on a dependent variable will be reliant on the second independent variable or moderator. In practice, a moderating model is supported if the interaction between two variables is significantly associated with a predictor variable (Baron \& Kenny, 1986).

\section{RESULTS}

Ninety-eight individuals were categorized into the high $(n=46)$ and low job strain $(n=52)$ groups. The characteristics of the participants and questionnaire data are summarised and presented in Table 1 . There were no significant differences between the groups with respect to sex, age, teaching experience, or the number of hours worked at home during the evening of testing. The average reported sleep time was 6 hours and 48 minutes. There were no significant difference between the groups in reported sleep time, but high job strain teachers reported poorer 
sleep, relative to low job strain teachers. Consistent with the gender ratio of school teachers in the UK, there were more females than males in each group. By design there was a significant difference in job strain between the high/low job strain groups.

\section{Ruminative thought}

Ratings of work rumination over the workday evening revealed a significant main effect of Group $(\mathrm{F}(1,96)=7.13, \mathrm{p}<0.01)$, and Time $(\mathrm{F}(6,96)=82.3, \mathrm{p}<0.001)$, but there was no significant Group $x$ Time interaction $(F(1,96)=1.23$, ns). These means are shown in Figure 1. Compared to ratings made at 5 pm, work rumination was significantly lower at 6 pm, 7 pm, 8 pm, 9 pm, 10 pm and bedtime (all ps <0.001). Ratings of work rumination at bedtime were significantly lower compared to those made at 6 pm, 7 pm, 8 pm, 9 pm and 10 pm (all ps <0.05). Overall, these results demonstrate that work rumination was greatest early in the evening but then declined thereafter until bedtime.

\section{Correlational Analyses}

For the correlational analyses all the variables were treated as continuous and the data from all the participants were used. Neither job strain, nor sleep quality was significantly correlated with any of the demographic variables. Work rumination was significantly correlated with marital status; married or living with a partner was associated with reporting less work rumination in the hour preceding bed. Sleep quality was significantly correlated with sleep time; longer sleep time was associated with higher sleep quality. Sex was not significantly correlated with any variable. The complete correlation matrix is presented in Table 2.

\section{Test for mediation}

Consistent with the hypothesised first mediation step, job strain was significantly correlated with sleep $(r=-.18, \mathrm{p}<0.01)$ as higher job strain scores were associated with reduced sleep quality. The second step was also supported - job strain was significantly correlated with work rumination 
in the hour preceding sleep, in the predicted direction i.e., higher job strain scores were associated with greater rumination $(r=.18, \mathrm{p}<0.05)$. Work rumination was also significantly associated with reduced sleep quality supporting step $3(r=-.24, \mathrm{p}<0.001)$. In the fourth and crucial last step, job strain failed to significantly predict sleep quality once the variance associated with rumination was controlled $(\beta=-.15, t=-1.71, \mathrm{p}=0.08)$, although work rumination continued to be significantly associated with sleep quality after controlling for the variance associated with job strain $(\beta=-.21, t=-2.65, \mathrm{p}<0.01)$. However as the reduction in beta was very small for job strain once work rumination was added to the model (.03), the present, results therefore, do not support our hypothesis that work rumination mediates the path between job strain and sleep quality.

\section{Test for moderation}

To test the interaction hypothesis, a hierarchical regression analysis was performed following mean centring and the creation of a multiplicative (cross-product) term (Aiken \& West, 1991). This was to eliminate the possibility of multicollinearity between the main effects and the interaction effect on sleep. The order of entry was job strain and work rumination in the hour preceding bed, and then the interaction (job strain x work rumination) term. There was a significant main effect of job strain $(\beta=-.18, t=-2.28, \mathrm{p}<0.05)$, and a significant main effect of work rumination $(\beta=-.21, t=-2.13$, $\mathrm{p}<0.05)$, but the job strain $\mathrm{x}$ work rumination interaction was non significant ( $\beta=-.14, t=-1.42$, ns.). Thus the effect of job strain on sleep quality was not moderated by work rumination.

\section{DISCUSSION}

The main objective of this study was to examine the relationship between job strain, work rumination and subjective sleep in a population of school teachers. Consistent with the previous findings of Cropley \& Millward Purvis (2003), and Hypothesis 1, work rumination was higher in 
the early evening and declined as the evening progressed as individuals gradually unwound and relaxed. Also as expected, high job strain teachers, demonstrated a greater likelihood of ruminative thinking, across the whole evening, relative to low job strain teachers. This finding could not be explained by work patterns as there was no difference between the groups in the time spent on school work over the evening. Given that teaching is regarded as a high stress occupation (Travers \& Cooper, 1996), it is perhaps not surprising that some teachers failed to successfully 'switch-off' and disengage from work related issues during their leisure time. Unlike previous research however, there was no interaction between job strain and work rumination.

Workers in demanding jobs frequently complain of sleep disturbance and many attribute this to thinking about work related thoughts at bedtime and during the night (Kecklund \& Åkerstedt, 2004). In the present study we predicted that ruminating about work issues in the hour preceding bedtime would be associated with greater sleep disturbance. This expectation was supported: job strain and work rumination were negatively associated with sleep quality. However, against expectations (Hypothesis 2), work rumination did not mediate or moderate the relationship between job strain and sleep quality in the present study. Unfortunately, the initial path between job strain and sleep quality was relatively low at $r=-.18$, and once work rumination was added to the model, the beta value was only reduced by a very small amount .03 . One possible reason for this could be the job strain measure used in the study. The job strain measure was more of a trait questionnaire, seeking information about perceptions of working environment in general, and future research may find a stronger correlation with sleep quality if a state or specific measure of job strain was used to seek information about how stressful the job was that day.

Interestingly there was no difference in reported sleep time between the high and low job strain teachers. The mean sleep length was 6 hours and 38 minutes. This figure is lower than reported nationally (Groeger, Zijlstra, \& Dijk, 2004), and indicates that many teachers have restrictive sleep - at least within the working week. It is possible that some teachers compensate 
and make up lost sleep at the weekend, although, at the moment, this is speculative. Care however should be exercised in the interpretation of this result until it is qualified by more objective measures and future research could try to validate the findings by using more objective sleep measures like sleep actigraphy (Stanley, 2003), or sleep polysomnography. A recent study found a reduction of slow wave sleep (SWS) in working individuals who were apprehensive about their work the following day (Kecklund \& Åkerstedt, 2004).

We assume that ruminating about work issues in the hour before bed raises cognitive and physiological arousal of the central nervous system, and being highly aroused delays sleep onset and leads to poorer sleep. Laboratory studies have shown that individuals who ruminate following the completion of a challenging task, tend to show prolonged physiological arousal (Roger \& Jamieson, 1988), and being aroused at bedtime delays sleep onset (Gross \& Borkovec, 1982; Harvey, 2000; Harvey \& Payne, 2002). The present findings are consistent with this work. Unfortunately, it was not possible to take physiological readings in the above study so the link between rumination, and autonomic arousal on sleep quality could not be established. It will be of theoretical interest to validate the rumination questions against physiological measures by showing higher ruminative thinking to be associated with high levels of arousal. Conversely reducing or blocking ruminative thought should result in lower arousal and improved sleep quality.

Although not one of the major objectives, we also examined the role of sex with respect to work rumination. It was interesting that sex was not significantly correlated with rumination. Nolen-Hoeksema (1987) in her work on depressive rumination, found women to show more ruminative thinking then men. It has been speculated that one reason for this is because women face different sources of stressors compared to men. Women have also been shown to become more distressed over home/family demands, while men become distressed over work matters (Almeida \& Kessler, 1998; Conger, Lorenz, Elder, Simons, \& Ge, 1993). It is not clear why there was no difference between men and women with regards to their ruminative responses in the 
present study, although one possibility is that because they came from a single occupation group, they experience similar stresses and strains - particularly at work. However, caution needs to be exercised here, as there were fewer men in the study and this could have been the main reason for not finding sex differences.

It is not only those individuals who experience high job strain who may think about work issues during free time. People who perceive their jobs as rewarding, stimulating, and challenging may also find themselves thinking about work issues during their leisure time. Indeed, repeatedly thinking about a certain area of work may be welcomed by some, as it will help them stay focussed on the task at hand. Although such ways of thinking may appear effectual, particularly in the short term, the continual emphasis on work at the cost of not attending to 'other spheres of life’ may eventually lead to stress (Griffith, Steptoe, \& Cropley, 1999). The rumination questions in the present study sought information only about work related thoughts but no distinction was made concerning whether these thoughts were voluntary/involuntary or intrusive. Here rumination was considered as a form of cognitive arousal; the emotionality of the thoughts was not assessed. Negative pre-sleep cognitive activity has been associated with certain sleep parameters in some studies (Harvey, 2000). In order to extend our understanding of these issues, further research is needed to examine not only the level of cognitive activity at bedtime but also the emotional content and the level of control an individual has over such thoughts. A greater understanding of these issues is needed as this will aid interventions aimed at improving sleep quality in stressed workers.

A potential problem with using pen and pencil diaries it that researchers can never be certain that study participants completed the questions at the times requested, and this could be a limitation with the present study. It was reassuring that the results mirrored an earlier study (Cropley , Millward Purvis, 2003), however future work could use electronic diaries to record the exact time entries are made to address this issue. There are other limitations of this study that warrant discussion. The present results are essentially correlational. Demonstrating an association 
between work rumination and sleep quality does not mean that rumination about work issues causes sleep problems. Poor sleep could effect one's perceptions of work or lower work performance, leading people to ruminate about work issues during their leisure time. To demonstrate causality, an experiment is required where manipulations of work ruminative thinking produce variations in sleep quality. Another limitation concerns other factors that could possibly affect sleep. It is well known that sleep can be disrupted by a number of sleepinterfering factors like caffeine intake, light, noise, and stressful life events (excluding work) and none of those variables were measured in the present study. In order to keep the diary short and not to overburden participants it was impractical to measure all the factors that are known to effect sleep. The very fact that sleep quality was associated with work rumination, despite not controlling for these other factors, demonstrates how pervasive the relationship between work rumination and sleep is.

Finally, this study was performed with school teachers and school teaching is a high commitment occupation (Aronsson et al., 2003), so it is not known whether the results will generalise to other occupational groups. Relative to many occupations, school teachers are thought to work long hours at home, and are distracted by work related issues while at home (Cardenas, et al., 2004), and therefore have less time to recover and unwind. There are, however, no logical reasons why the results should not generalise especially in other professional groups of workers, e.g., accountants, health practitioners, or the police, or in occupations where there are blurred boundaries between home and work. Further research with other occupational groups is undoubtedly needed.

The validity of these findings ultimately depends on their representativeness. The measurement of work rumination may be seen as being problematic as it may implicitly encourage introspective thought. The question therefore arises: do people behave or sleep as 'normal' at night after completing a diary assessment which prompts them to think about work 
issues? We do not know the answer to this question but $71 \%$ of the sample rated their sleep as typical, and $19 \%$ as not typical for that night.

In conclusion, this study has demonstrated that ruminative thinking about work issues at bedtime can predict perceptions of sleep quality. These results suggest that suitable methods aimed at disrupting, reducing, or blocking this style of thinking would result in a better quality of sleep for workers. Future research is needed to ascertain how best to do this. Many teachers take work home and the interface between work and home boundaries is blurred. Working at home does not necessarily translate into poor sleep, how easily one is able to 'switch-off' once work is completed appears to be the crucial factor which predicts good quality sleep. 


\section{REFERENCES}

Aiken, L. S. and West, S. G. (1991). Multiple regression: Testing and interpreting interactions. Newbury Park, CA: Sage.

Åkerstedt, T., Hume, K., Minors, D., \& Waterhouse, J. (1994). The meaning of good sleep: a longitudinal study of polysomnography and subjective sleep quality. Journal of Sleep Research, 3, 152-158.

Åkerstedt, T., Knutsson, A., Westerholm, P., Theorell, T., Alfredsson, L., \& Kecklund, G. (2002). Sleep disturbances, work stress and work hours: a cross-sectional study. Journal of Psychosomatic Research, 53, 741-748.

Alloy, L.B., Abramson, L.Y., Hogan, M.E., Whitehouse, W.G., Rose, D.T, Robinson, M.S., Kim, R.S., \& Lapkin, J.B. (2000). The Temple-Wisconsin Cognitive Vulnerability to Depression Project: lifetime history of axis I psychopathology in individuals at high and low cognitive risk for depression. Journal of Abnormal Psychology, 109, 403-18.

Almeida, D. M., \& Kessler, R. C. (1998). Everyday stressors and gender differences in daily distress. Journal of Personality and Social Psychology, 75, 670-680.

Aronsson, G., Svensson, L., \& Gustafsson, K. (2003). Unwinding, recuperation and health among compulsory-school and high-school school teachers in Sweden. International Journal of Stress Management, 10, 217-234.

Baron, R.M., \& Kenny, D.A. (1986). The moderator-mediator variable distinction in social psychological research: conceptual, strategic, and statistical considerations. Journal of Personality and Social Psychology, 51, 1173-1182.

Belkic, K.L., Landsbergis, P.A., Schnall, P.L., \& Baker, D. (2004). Is job strain a major source of cardiovascular disease risk? Scandinavian Journal of Work, Environment \& Health, 30, 85128. 
Bertelson, A.D., \& Monroe, L.J. (1979). Personality patterns of adolescent poor and good sleepers. Journal of Abnormal Child Psychology, 7, 191-197.

Cardenas, R. A., Major, D. A., \& Bernas, K. H. (2004). Exploring work and family distractions: Antecedents and outcomes. International Journal of Stress Management, 11, 346-365. Conger, R.D., Lorenz, F.O., Elder, G.H., Jr., Simons, R.L., \& Ge, X.(1993). Husband and wife differences in response to undesirable life events. Journal of Health and Social Behavior, 34, 71-88.

Cropley, M., \& Millward Purvis, L.J. (2003). Job Strain And Rumination About Work Issues During Leisure Time: A Diary Study. European Journal of Work and Organizational Psychology, 12, 195-207.

Cropley, M., Steptoe, A., \& Joekes, K. (1999). Job strain and psychiatric morbidity. Psychological Medicine, 29, 1411-1416.

Dinges, D.F, Pack, F., Williams, K., Gillen, K.A., Powell, J.W., Ott, G.E., Aptowicz, C., \& Pack, A.I. (1997). Cumulative sleepiness, mood disturbance, and psychomotor vigilance performance decrements during a week of sleep restricted to 4-5 hours per night. Sleep, 20, 267-277.

Evans, O., \& Steptoe, A. (2001). Social support at work, heart rate, and cortisol: a selfmonitoring study. Journal of Occupational Health Psychology, 6, 361-370.

Evans, O., \& Steptoe, A. (2002). The contribution of gender-role orientation, work factors and home stressors to psychological well-being and sickness absence in male- and femaledominated occupational groups. Social Science \& Medicine, 54, 481-492.

Griffith, J., Steptoe, A., \& Cropley, M. (1999). An investigation of coping strategies associated with job stress in teachers. British Journal of Educational Psychology, 69, 517-531.

Groeger, J.A., Zijlstra, F.R.H., \& Dijk, D-J. (2004). Sleep quantity, sleep difficulties and their perceived consequences in a representative sample of some 2000 British adults. Journal of Sleep Research, 13, 359-371. 
Gross, R.T., \& Borkovec, T.D. (1982). The effects of a cognitive intrusion manipulation on the sleep-onset latency of good sleepers. Behaviour Therapy, 13, 112-116.

Harrison, Y., \& Horne, J.A. (1999). One Night of Sleep Loss Impairs Innovative Thinking and Flexible Decision Making. Organizational Behaviour and Human Decision Processes, 78, 128-145.

Harvey, A.G. (2000). Pre-sleep cognitive activity: a comparison of sleep-onset insomniacs and good sleepers. British Journal of Clinical Psychology, 39, 275-286.

Harvey, A.G., \& Payne, S. (2002). The management of unwanted pre-sleep thoughts in insomnia: distraction with imagery versus general distraction. Behavior Research \& Therapy, 40, 267277.

Higgins, J.E., \& Endler, N. S. (1995). Coping, life stress, and psychological and somatic distress. European Journal of Personality, 9, 253-270.

Hogan, B.E., \& Linden, W. (2004). Anger response styles and blood pressure: at least don't ruminate about it! Annals of Behavioral Medicine, 27, 38-49.

Jewett, M.E., Dijk, DJ., Kronauer, R.E., \& Dinges, D.F. (1999). Dose-response relationship between sleep duration and human psychomotor vigilance and subjective alertness. Sleep, $15,171-179$.

Kales, A., Caldwell, A.B., Soldatos, C.R., Bixler, E.O., \& Kales, J.D. (1983).

Biopsychobehavioral correlates of insomnia. II. Pattern specificity and consistency with the Minnesota Multiphasic Personality Inventory. Psychosomatic Medicine, 45, 341-356.

Karasek, R.A., \& Theorell, T. (1990). Healthy Work. New York: Basic Books.

Kecklund, G., \& Åkerstedt, T. (2004). Apprehension of the subsequent working day is associated with a low amount of slow wave sleep. Biological Psychology, 66, 169-176.

Lazarus, R. S., \& Folkman, S. (1984). Stress, appraisal, and coping. New York: Springer. 
Lyubomirsky, S., Tucker, K.L., Caldwell, N.D., \& Berg, K. (1999). Why ruminators are poor problem solvers: clues from the phenomenology of dysphoric rumination. Journal of Personality and Social Psychology, 77, 1041-1060.

Martin, L.L., \& Tesser, A. (1989). Toward a motivational and structural theory of ruminative thought. In J. Uleman and J.A. Bargh (Eds), Unintended thought (pp.306-326). New York: Guilford Press.

Mellings, T.M.B., \& Alden, L.E. (2000). Cognitive processes in social anxiety: the effects of selffocus, rumination and anticipatory processing. Behaviour Research and Therapy, 38, 24357.

Nolen-Hoeksema, S. (1987). Sex differences in unipolar depression: evidence and theory. Psychological Bulletin, 101, 259-282.

Nolen-Hoeksema, S. (1991). Responses to depression and their effects on the duration of depressive episodes. Journal of Abnormal Psychology, 100, 569-82. Review.

Nolen-Hoeksema, S., McBride, A., \& Larson, J. (1997). Rumination and psychological distress among bereaved partners. Journal of Personality and Social Psychology, 72, 855-862.

Papageorgiou, C., \& Wells, A. (2004). Nature, functions, and beliefs about depressive rumination. In C. Papageorgiou \& A. Wells (eds.), Depressive rumination: Nature, theory and treatment (pp. 3-20). New York: Wiley.

Rau, R., Georgiades, A., Fredrikson, M., Lemne, C., \& de Faire, U. (2001). Psychosocial work characteristics and perceived control in relation to cardiovascular rewind at night. Journal of Occupational Health Psychology, 6, 171-181.

Robinson, M.S., \& Alloy, L.B. (2003). Negative cognitive styles and stress-reactive rumination interact to predict depression: A prospective study. Cognitive Therapy and Research, 27, 275-291. 
Roger, D., \& Jamieson, J. (1988). Individual differences in delayed heart-rate recovery following stress: the role of extraversion, neuroticism and emotional control. Personality and Individual Differences, 9, 721-726.

Rogers, N.L., Szuba, M.P., Staab, J.P., Evans, D.L., \& Dinges, D.F. (2001). Neuroimmunologic aspects of sleep and sleep loss. Seminars in Clinical Neuropsychiatry, 6, 295-307.

Rusting C.L., \& Nolen-Hoeksema, S. (1998). Regulating responses to anger: effects of rumination and distraction on angry mood. Journal of Personality \& Social Psychology, 74, 790-803.

Sadeh, A., Keinan, G. \& Daon, K. (2004). Effects of stress on sleep: the moderating role of coping style. Health Psychology, 23, 542-545.

Stanley, N. (2003). Actigraphy in human psychopharmacology: a review. Human Psychopharmacology, 18, 39-49.

Stansfeld, S.A., North, F.M., White, I., \& Marmot, M.G. (1995). Work characteristics and psychiatric disorder in civil servants in London. Journal of Epidemiology and Community Health, 49, 48-53.

Steptoe, A. (1991). Invited review. The links between stress and illness. Journal of Psychosomatic Research, 35, 633-644.

Steptoe, A., Cropley, M., \& Joekes, K. (1999). Job strain, blood pressure, and response to uncontrollable stress. Journal of Hypertension, 17, 193-200.

Thomsen, D.K., Mehlsen, Y.M., Christensen S., \& Zachariae, R. (2003). Rumination relationship with negative mood and sleep quality, Personality and Individual Differences, 34, 1293-1301.

Thomsen, D.K., Mehlsen, M.Y., Olesen, F., Hokland, M., Viidik, A., Avlund, K. \& Zachariae, R. (2004). Is there an association between rumination and self-reported physical health? A one-year follow-up in a young and an elderly sample. Journal of Behavioural Medicine, 27, 215-231. 
Travers, C.J., \& Cooper, C.L. (1996). Teachers under pressure: stress in the teaching profession. London: Routledge.

Walsh, J.K., \& Lindblom, S.S. (2000). Psychophysiology of sleep deprivation and disruption. In M.R. Pressman \& W.C. Orr. (Eds), Understanding sleep: the evaluation and treatment of sleep disorders (pp. 73-110). Washington, DC, USA: APA. 
Table 1 Participants characteristics in the low and high job strain groups 
Low job strain

$$
(\mathbf{n}=52)
$$

Sex

Male

Female

Age (years)

School Type (\%)

Primary

Secondary

Years of teaching

Minutes worked at home that evening

Total sleep time (hrs/minutes)

Sleep Quality

Job Strain
5

47

$38.1(12.1)$

75

25

$12.6(11.0)$

$72.6(60.9)$

$6.41(0.9)$

$5.1(1.2)$

$10.4(1.5)$
High job strain

$$
(\mathrm{n}=46)
$$

39

$42.2(10.3)$

72

28

$16.3(10.7)$

$93.9(82.6)$

$6.28(1.0)$

$4.3(1.4)^{* *}$

$15.4(1.8)^{* *}$

(standard deviation in parenthesis) $* \mathrm{p}<0.05,{ }^{* *} \mathrm{p}<0.001$ difference between groups 
Table 2 Bivariate correlations between demographic, work, work rumination at bedtime and sleep quality variables 
Age Sex MStatus YearsT HomeW SleepT JStrain RumB

Age

Sex $\quad-.02$

MStatus $\quad-.34 * * \quad .08$

YearsT $\quad .84^{* *} \quad-.05 \quad-.31^{* *}$

HomeW $\quad .14 \quad-.01 \quad-.17^{*} \quad .03$

$\begin{array}{llllll}\text { SleepT } & -.39 * * & -.12 & .12 & -.32 * * & .03\end{array}$

$\begin{array}{lllllll}\text { JStrain } & .06 & .07 & -.15 & .10 & .10 & -.11\end{array}$

$\begin{array}{llllllll}\text { RumB } & .02 & -.02 & -.20 * & .03 & .13 & -.21 * * & .18 *\end{array}$

$\begin{array}{llllllllll}\text { SleepQ } & -.07 & .06 & .13 & -.01 & .06 & .28 * * & -.18^{*} & -.24 * *\end{array}$

$*=\mathrm{p}<0.05 ; * *=\mathrm{p}<0.01$

Sex = 1 male, 2 female; MStatus = Marital Status (1 married or living with partner, 2 single);

YearsT $=$ years teaching, $\mathrm{HomeW}=$ time working at home during the evening; SleepT $=$ total sleep time, JStrain job strain, RumB = Work rumination at bedtime, SleepQ $=$ Sleep quality . 
Figure 1 Rumination about work during the evening from $5 \mathrm{pm}$ to Bedtime in high and low job strain individuals 


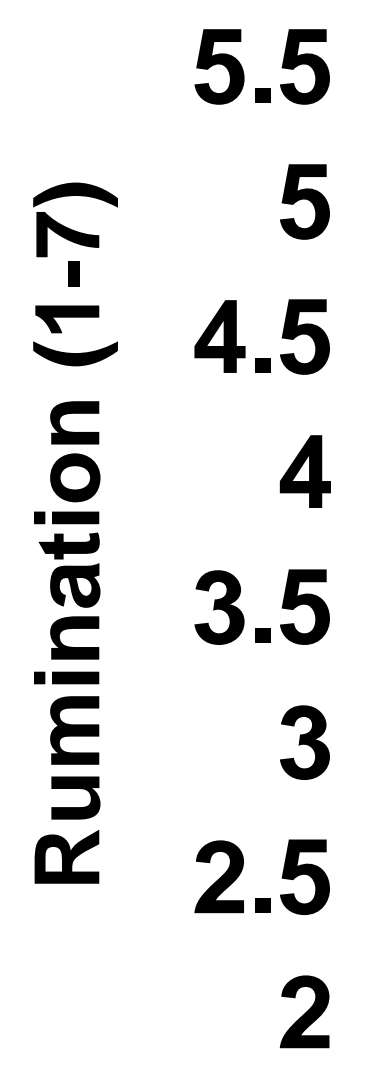

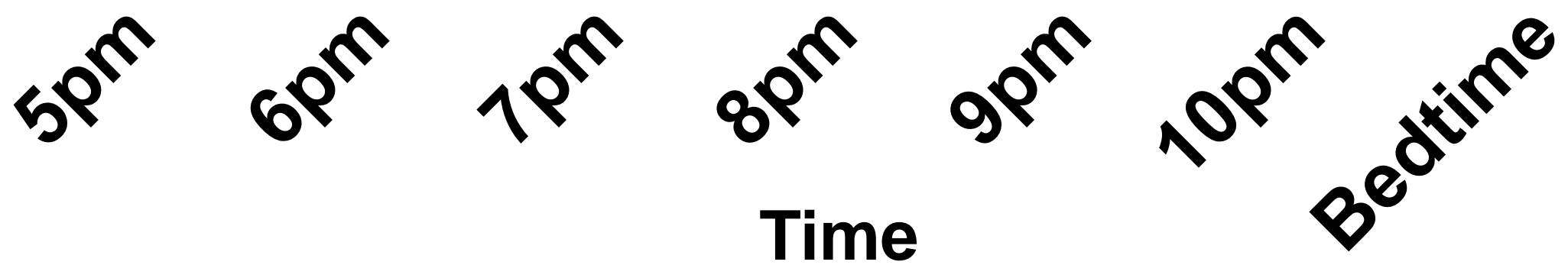

